\title{
A Short Term Review of Congenital Birth Defects at a Tertiary Care Hospital in the Eastern Region of Nepal
}

\author{
Ramesh Shrestha*1, Madan Khadka1, Sanyukta Rajbhandary ${ }^{1}$, Anamika Das ${ }^{1}$, \\ Sapana Shrestha², Jyoti Agrawal ${ }^{3}$
}

${ }^{1}$ Assistant professor, Department of Obstetrics and Gynaecology, B. P. Koirala Institute of Health Sciences, Dharan, Nepal. ${ }^{2}$ Master in Nursing, Women's Health and Development, Maharajgunj Nursing Campus, Kathmandu, Nepal. ${ }^{3}$ Associate professor, Department of Pediatrics, B. P. Koirala Institute of Health Sciences, Dharan, Nepal.

\begin{abstract}
Introduction: Birth defect refers to any abnormality of physical structure or form or function of prenatal origin, whether genetic or not, which is present at birth. Congenital birth defect is one of the causes of perinatal morbidity and mortality especially in developed countries. Studies of congenital birth defects are useful to establish baseline data, document changes over time and identify clues to etiology. This study was aimed to determine the overall prevalence of newborns with congenital birth defects, outcomes of those babies at birth, modes of delivery as well as various organ systems involved. Methods: It is a short term observational study conducted in the Department of Obstetrics and Gynaecology, B.P. Koirala Institute of Health Sciences, Dharan from July, 2016 to December, 2016 after ethical approval. All the intramural deliveries after 22 weeks of gestation in six months were looked for gross congenital birth defects soon after birth through meticulous examination. Antenatal sonographic documentation of fetal anomalies was noted and correlated after birth. The birth defects were categorized according to the ICD10 th Revision of birth defects. Results: During the study duration, there was a total of 6,496 births out of which 26 babies had birth defects. All the babies were delivered to mothers of age less than 35 years with no history of parental consanguinity. 11 (42.3\%) babies were born to mothers with no folic acid supplementation and three (11.5\%) babies had ambiguous sex. Most of them (22; 84.6\%) were alive at birth and majority of them born vaginally $(19 ; 73.0 \%)$ and had normal birth weight $(18 ; 69.2 \%)$. Majority of them had defects detected incidentally after delivery $(19 ; 73.0 \%)$ and were non-lethal. The most common birth defect was related to central nervous system $(12 ; 46.15 \%)$. Conclusions: In this study, the prevalence of congenital birth defects was $0.4 \%$. Majority of the birth defects (73.0\%) were detected after delivery. Most of the babies with defects (84.6\%) were alive at birth and non-lethal. The most common birth defects were related to central nervous system (46.15\%). Hence, preconceptional counselling and folic acid supplementation are recommended for prevention, termination for lethal defects and surgical repairs of non-lethal defects for viable newborns after delivery.
\end{abstract}

Keywords: Birth defects, congenital, intramural, review, termination.

* Address of Correspondence: Dr. Ramesh Shrestha. Affiliation: Assistant professor, Department of Obstetrics and Gynaecology, BPKIHS, Dharan, Nepal. Email address: stharamesh007@gmail.com (Received 17 January 2020; revised 22 January 2020; accepted 24 January 2020) 


\section{Introduction}

Congenital birth defect refers to any abnormality, whether genetic or not, which is present at birth (1). It can also be defined as abnormality of physical structure or form seen at birth or few weeks after birth (2).

Congenital birth defects are categorized into three groups based on the causes, timing and extent of the developmental disturbance:

\section{Malformations (defective organogenes-is)}

2. Dysplasia (abnormal cell or tissue structure)

3. Deformation (mechanically induced changes of normal structure) (3).

Primary malformations are due to endogenous disturbances of primordial tissues. Secondary malformations (disruption) occur when organs develop abnormally from a normal primordium. A distinction is drawn between singular (isolated) malformation, combined malformations (more than one malformation in a single organ category in one individual), multiple malformations (more than one malformation in different organ system in one individual) and syndromes (combination of developmental defects showing a common etiology). Major congenital birth defects are structural defects of the body and organs that impair viability of the babies and require intervention. Minor congenital birth defects are small structural developmental disturbances that do not impair viability of the babies and do not need to be treated. About $20 \%$ of all major congenital birth defects are transmitted genetically (monogenetic), 5-10\% are due to chromosomal anomalies, $2-10 \%$ are due to viral infection. The causes in $60 \%$ are unknown and appear to be multifactorial (4).

In developed countries, congenital birth defects are a leading cause of perinatal death. In developing countries like ours, the leading causes of neonatal mortality are infection and low birth weight. In the coming decades due to improved perinatal and neonatal care, mortality due to sepsis and low birth weight might be reduced remarkably and congenital birth defects might become a leading cause of neonatal mortality. Studies of congenital birth defects are useful to establish baseline data, to document changes over time and to identify clues to etiology. They are also important for health service planning and evaluating antenatal screening in population with high risk. Such studies help to identify the etiological factors whether it is modifiable or nonmodifiable, emphasize on prenatal diagnosis and raise the awareness of surgical intervention to correct them and notify babies with both major and minor birth defects and perinatal loss for public health issues. There are few studies done within the hospital setups within the Kathmandu valley regarding prevalence, types and outcomes of babies with congenital malformations but such study had not been done outside the capital city or in our centre lacking robust data on the congenital birth defects.

\section{Aims of the Study}

This study was conducted to determine the overall prevalence of newborns with congenital birth defects, outcomes of those babies at birth, modes of delivery as well as various organ systems involved.

\section{Materials and Methods}

It was a short term observational study conducted in the Department of Obstetrics and Gynaecology, BPKIHS, Dharan over the study duration of six months from July, 2016 to December, 2016 after obtaining ethical approval from the Institutional Review Committee, BPKIHS.

\section{Inclusion criteria}

All the intramural deliveries after 22 weeks of gestation in the Department of Obstetrics and Gynaecology in the six months' duration comprised the study population.

\section{Exclusion criteria}

All the extramural deliveries with birth defects and referred to BPKIHS for better care and pediatrics surgery were excluded from the study. All the newborns (live births, intrauterine deaths and still births) were looked for gross congenital anomalies in the delivery (labour or operating) room after ini- 
tial resuscitation and stabilization through meticulous general and systematic examinations as well as expert opinions from the pediatricians if needed. Relevant baseline data regarding maternal age, gestational age, multiple birth, baby's sex, birth weight, first trimester folic acid supplementation, mode of delivery, status of baby at birth and parental consanguinity were documented. Relevant antenatal history like maternal illness, ingestion of teratogenic drugs, radiation exposure was also recorded. Antenatal sonographic documentation of fetal anomalies was noted and correlated after birth. Any defects noticed after birth but not detected in-utero were also recorded.

The congenital malformations were categorized according to the International Statistical Classification of Diseases and Related Health Problems $10^{\text {th }}$ Revision.

- Q00-Q07: Congenital malformations of the nervous system

- Q10-Q18: Congenital malformations of eye, ear, face and neck

- Q20-Q28: Congenital malformations of the circulatory system
- Q30-Q34: Congenital malformations of the respiratory system

- Q35-Q37: Cleft lip and palate

- Q38-Q45: Other congenital malformations of the digestive system

- Q50-Q56: Congenital malformations of genital organs

- Q60-Q64: Congenital malformations of the urinary system

- Q65-Q79: Congenital malformations and deformations of the musculoskeletal system

- Q80-Q89: Other congenital malformations

- Q90-Q99: Chromosomal abnormalities, not elsewhere classified

\section{Results}

During the study duration of six months, there was a total of 6,496 births out of which 6,371 were live born, 125 were still born and 26 had congenital birth defects. Hence, the prevalence of congenital birth defects among the intramural deliveries at this institute was $0.4 \%$ (Table 1 ).

Table 1: Monthly profile of total deliveries, live births, still births and birth defects

\begin{tabular}{|l|l|l|l|l|}
\hline MONTH, YEAR & TOTAL BIRTHS & LIVE BIRTHS & $\begin{array}{l}\text { STILL BIRTHS } \\
\text { (Fresh + Macerated }\end{array}$ & BIRTH DEFECTS \\
\hline JULY, 2016 & 912 & 895 & $6+11=17$ & 4 \\
\hline AUGUST, 2016 & 1,155 & 1,132 & $6+17=23$ & 8 \\
\hline SEPTEMBER, 2016 & 1,197 & 1,169 & $11+17=28$ & 8 \\
\hline OCTOBER, 2016 & 1,149 & 1,121 & $11+17=28$ & 2 \\
\hline NOVEMBER, 2016 & 1,074 & 1,053 & $6+15=21$ & 2 \\
\hline DECEMBER, 2016 & 1,009 & 1,001 & $2+6=8$ & 2 \\
\hline TOTAL & $\mathbf{6 , 4 9 6}$ & $\mathbf{6 , 3 7 1}$ & $\mathbf{4 2 + 8 3 = 1 2 5}$ & $\mathbf{2 6}$ \\
\hline
\end{tabular}


Table 2: Socio-demographic characteristics of the mothers delivering babies with birth defects $(n=26)$

\begin{tabular}{|l|l|}
\hline CHARACTERISTICS & FREQUENCY (PERCENTAGE) \\
\hline $\begin{array}{l}\text { MOTHER'S AGE } \\
<35 \text { years }\end{array}$ & $26(100 \%)$ \\
\hline$\geq 35$ years & $0(0 \%)$ \\
\hline GESTATIONAL AGE & $6(23 \%)$ \\
\hline$<37$ weeks & $20(77 \%)$ \\
\hline$\geq 37$ weeks & $25(96 \%)$ \\
\hline MULTIPLE BIRTH & $1(4 \%)$ \\
\hline Single & \\
\hline Twin & $0(0 \%)$ \\
\hline PARENTAL CONSANGUINITY & $26(100 \%)$ \\
\hline Yes & \\
\hline No & $15(57.7 \%)$ \\
\hline FOLIC ACID SUPPLEMENTATION & $11(42.3 \%)$ \\
\hline Yes & \\
\hline No & \\
\hline
\end{tabular}

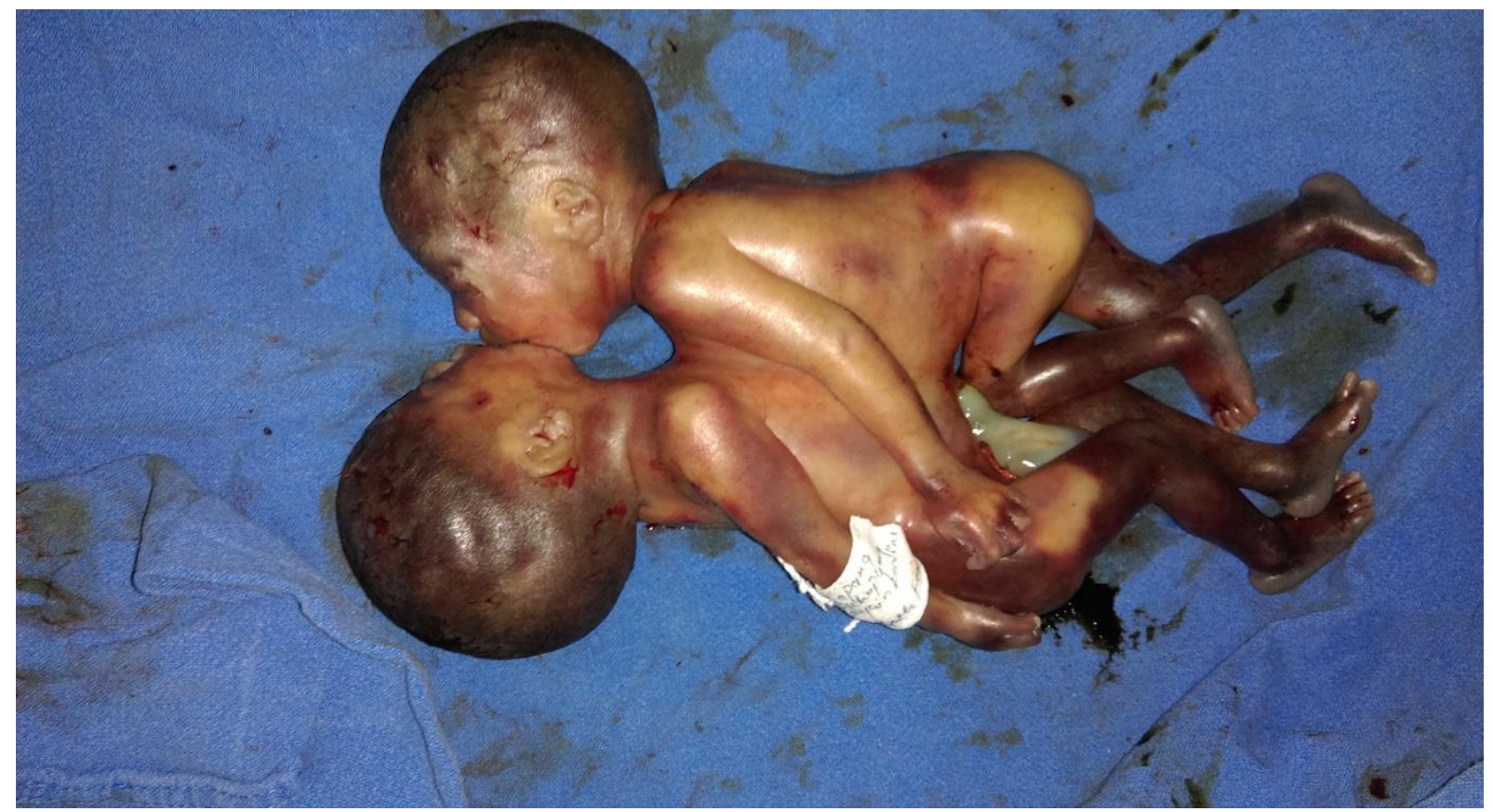

Figure 1: Conjoined or siamese twin-Thoracopagus 


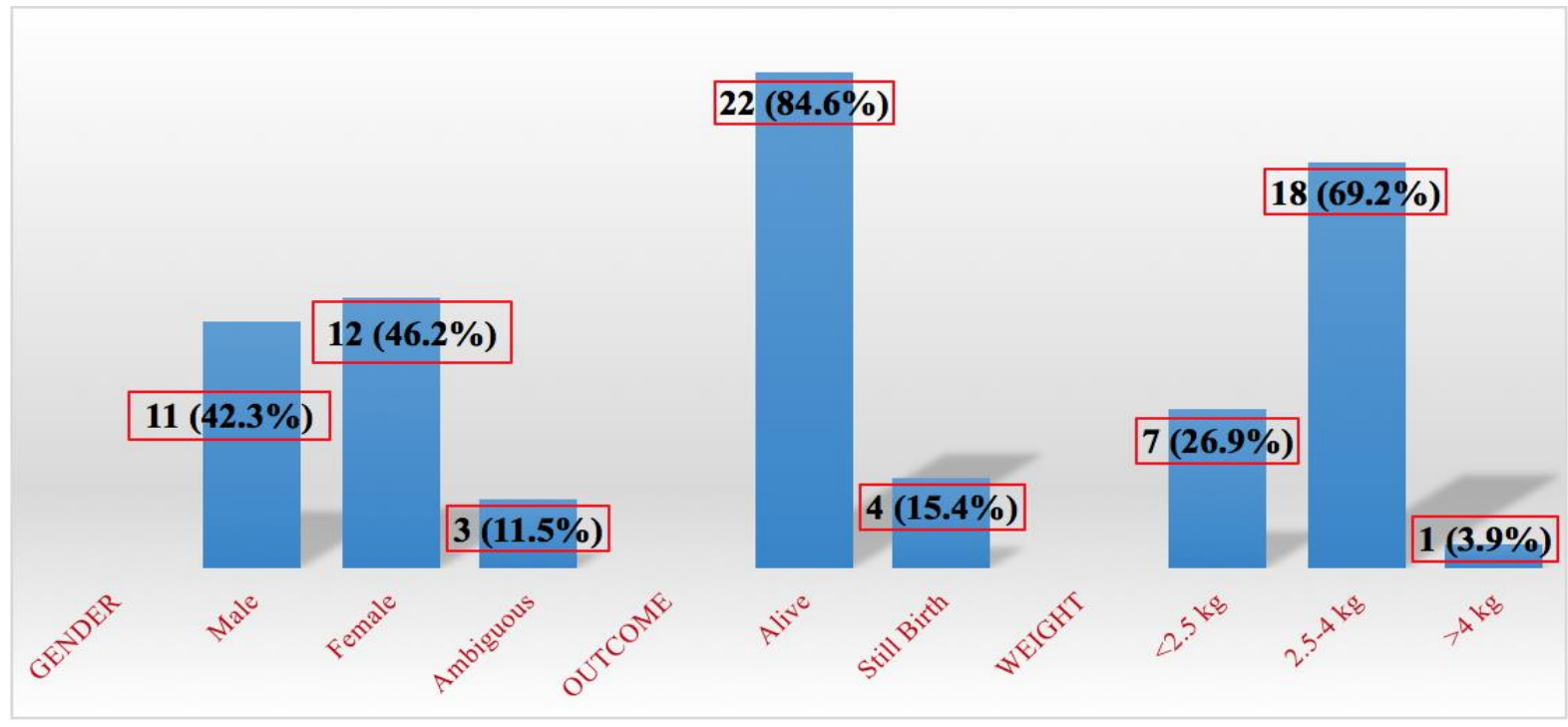

Figure 2: Demographic profile of babies with birth defects $(n=26)$

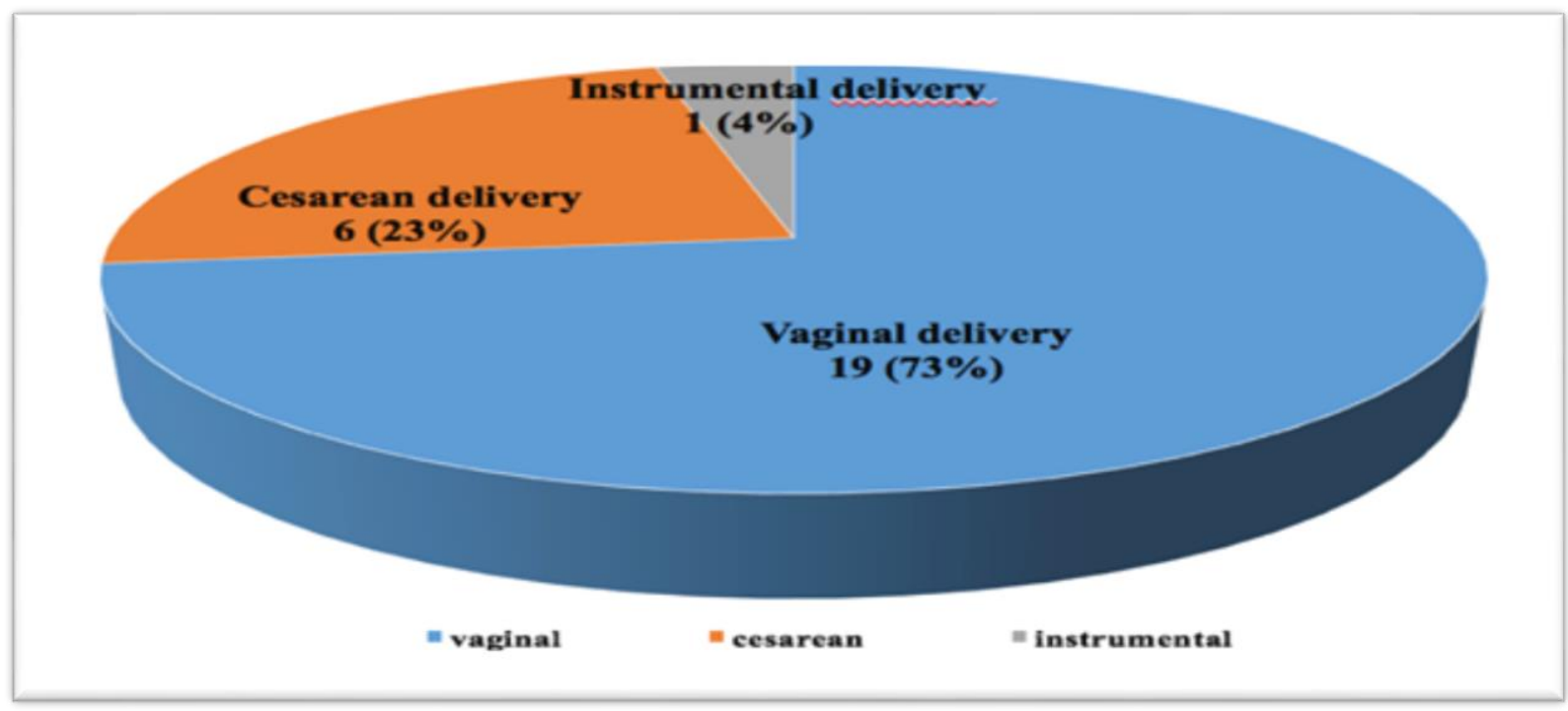

Figure 3: Mode of delivery $(\mathrm{n}=26)$

All the 26 babies with birth defects were delivered to mothers of age less than 35 years. There was no history of parental consanguinity and there was one baby of conjoined twin terminated at 24 weeks gestation (Fig. 1). 11 (42.3\%) babies with birth defects were born to mothers with no folic acid supplementation during the first trimester (Table 2).
Out of 26 babies, there were three (11.5\%) with ambiguous sex. Most of them (22; 84.6\%) were alive at birth and majority (18; 69.2\%) were of normal weight (Figure 2).

Majority of the babies $(19 ; 73.0 \%)$ were born vaginally while six (23.0\%) babies were born by cesarean section (Figure 3). 


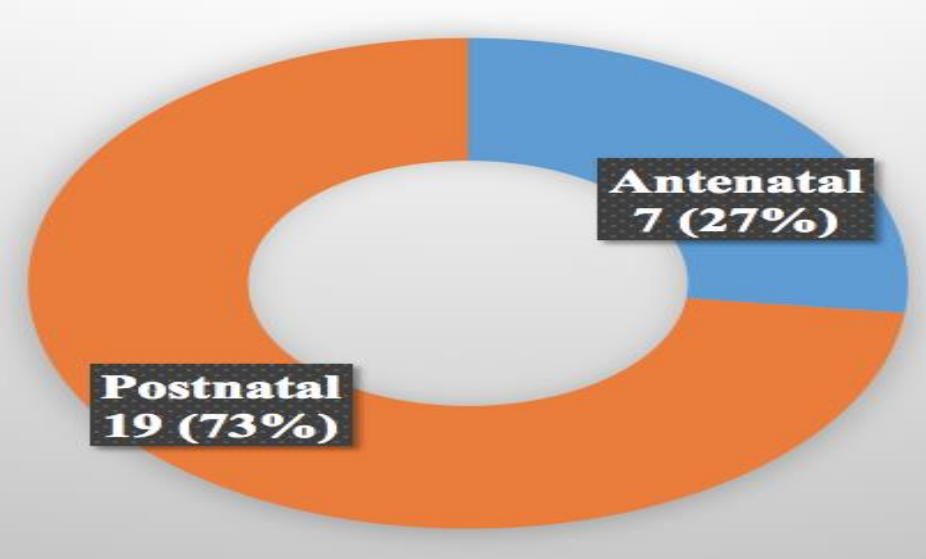

Figure 4: Time at diagnosis of birth defects $(n=26)$

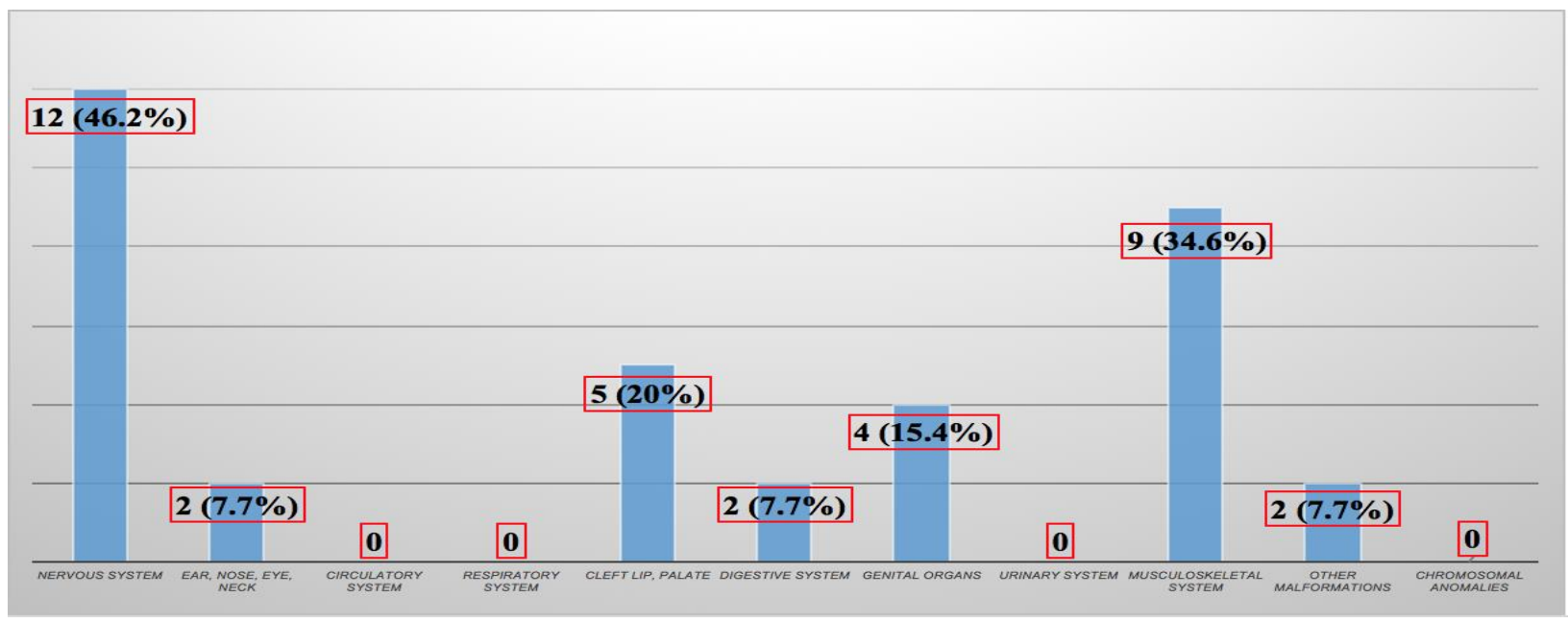

\section{Figure 5: ICD 10 Classification of birth defects $(n=26)$}

Among the 26 babies delivered with birth defects, majority of them had the defects detected after delivery $(19 ; 73.0 \%)$ (Figure 4).

The most common birth defects were related to central nervous system (12; 46.15\%) followed by musculoskeletal system (9; 34.61\%) and cleft lip and palate $(5 ; 19.23 \%)$ (Figure 5$)$.

\section{Discussions}

A total of 26 babies were delivered with birth defects accounting for the hospital based prevalence of $0.4 \%$. In this study, the prevalence of birth de- fects may be underestimated and it is in contrast to the studies done by Sarkar et al. (5) and Taksande et al. (6) in which the prevalence was $2.22 \%$ and $1.91 \%$ respectively. In this study, the organ system most commonly involved was central nervous system $(12 ; 46.2 \%)$ followed by musculoskeletal system $(9 ; 34.6 \%)$ and cleft lip and palate $(5 ; 20 \%)$ which is in contrast to the study by Sarkar et al. (5) in which the predominant system involved was musculo-skeletal system (33.2\%) followed by gastro-intestinal (GI) system (15\%) and central nervous system (CNS) (11.2\%). Similarly, in the study by Taksande et al. (6), cardiovascular malformations 
were most common in live births, followed by musculoskeletal malformations whereas CNS defects were most commonly seen in still born. However, the prevalence rate of congenital malformations in three different studies done by Ansari et al. (7), Malla et al. (8) and Ansari et al. (9) in institute based setups in Kathmandu, Nepal were similar to the finding of this study with their prevalence rate of $0.3 \%, 0.3 \%$ and $0.8 \%$ respectively. Similarly, Malla et al. (8) in their study found CNS followed by musculoskeletal system to be most commonly affected by birth defects which is similar to this study but in contrast, Ansari et al. (9) found musculoskeletal system to be the most commonly affected by birth defects.

In this study, all the babies with birth defects were born to mothers less than 35 years of age. There were three babies born with ambiguous genitalia and the sex ratio (Female:Male) of the babies with birth defects was 1.09:1. It is in contrast to the studies done by Sarkar et al. (5), Mohanty et al. (10) and Chaturvedi et al. (11) in which more male babies with congenital anomalies were noted. The finding of this study is similar to the study done by Sarkar et al. (5) in which majority of malformed babies were born to mothers aged 20-29 years but in contrast Suguna Bai et al. (12) reported a higher incidence of malformations in babies born to mothers aged over 35 years. Also, there was no history of parental consanguinity among the babies with birth defects in this study which is in contrast to the studies by Mathur et al. (13), Hudgins et al. (14), Madi et al. (15) and Al-Gazali et al. (16) in which the prevalence of malformed babies was more when born to consanguineous marriages. Taksande et al. (6) in his study reported that congenital malformations were seen more significantly in stillbirths $(P<0.01)$ as compared to live births, the frequency being $4.68 \%$ and $1.84 \%$, respectively which is in contrast to the present study in which the 22 (84.6\%) babies with birth defects were alive and $4(15.4 \%)$ babies were still born. In this study, 18 (69.2\%) babies with birth defects were of normal weight and $20(77.0 \%)$ babies with birth defects were term which is in contrast to the study done by Sarkar et al. (5) in which they reported that prematurity and LBW were found to have a higher risk of congenital anomalies.
The occurrence was about 4.5 times more in case of preterm delivery as compared with the term ones, making it statistically significant. Similarly, majority of the babies were delivered vaginally $(19 ; 73.0 \%)$ in this study which is in contrast to the study by Sarkar et al. (5) which showed that the mode of delivery was also significantly associated with congenital anomaly and it was more in case of cesarean deliveries. In this study, there was a case of conjoint twin among 6,496 total birth whereas in the study by Mutchinick et al. (17) the prevalence of conjoint twinning was 1.47 (95\% CI: 1.32-1.62) per 100,000 births.

\section{Limitations}

BPKIHS being a tertiary care referral centre, prevalence calculated might be underestimated than the general population because viable babies with birth defects delivered in the peripheral hospitals might have been referred to other nearby referral centres for surgical corrections. Also, non-viable babies with birth defects delivered without life might not have come to our notice. Secondly, the number of newborns with birth defects is relatively less to give a concrete conclusion. Thirdly, anomalies could not be searched for among abortions and stillborns because often the abnormalities are not obvious or visible externally. In those cases, a pathological autopsy is warranted needing parental consents which is technically difficult in our settings. Lastly, lack of biochemical screening markers and genetic testings at our centre to detect genetic or chromosomal abnormalities tends to make the study less fruitful.

\section{Conclusions}

In this study, the prevalence of congenital birth defects was $0.4 \%$. Majority of the birth defects (73.0\%) were detected after delivery and the most common birth defects were related to central nervous system (46.15\%). Most of the babies with defects $(84.6 \%)$ were alive at birth and the defects were not fatal mostly so that they could be corrected after surgical intervention. Hence, this study has highlighted the prevalence, time at detection and types of congenital anomalies seen in our centre. Preconceptional counselling, folic acid supplemen- 
tation in the first trimester during organogenesis, regular antenatal visits, prenatal screening and diagnosis with biochemical and sonological markers are recommended for prevention, early detection, timely termination of pregnancy for fatal defects and surgical repairs of non fatal defects for viable newborns after delivery. Also, there is a need of prospective studies over long study duration with scope to follow up every single child for six months or more may be required to assess true picture of congenital malformations.

\section{Acknowledgements}

I would like to acknowledge all the faculties of Department of Obstetrics and Gynaecology and Pediatrics and the respective residents for their help during the study and special thanks to the heads of both the Departments for their moral support.

\section{Funding}

Nil

\section{Conflict of Interest}

None

\section{References}

1. Turnpenny P, Ellard S. Congenital Abnormalities. Emerys' element of Medical Genetics $12^{\text {th }}$ edition; Edinburgh; Elseviers Churchill Livingstone; 2005;1-5.

2. Hudgins I, Cassidy SB. congenital malformations among live births at Arvand Hospital Ahwaz Iran. Pak J Med Sci. 2008;24:33- 37.

3. Spranger J, Berisrschkke K, Hall JG, Lenz W, Lowy RB, Opitz JM, Pinsky L, Schwarzacher HG, Smith DW. Errors in morphogenesis: Concepts and terms. J Pediatr. 1982;100:160-65.

4. Kalter H, Warkany J. Congenital malformations. Etiologic factors and their role in prevention. $\mathrm{N}$ Engl J Med. 1983;308(8):424-31.
5. Sarkar S, Patra C, Dasgupta MK, Nayek K, Karmakar PR. Prevalence of Congenital Anomalies in Neonates and Associated Risk Factors in a Tertiary Care Hospital in Eastern India. J Clin Neonatol. 2013;2(3):131-134.

6. Taksande A, Vilhekar K, Chaturvedi P, Jain M. Congenital malformations at birth in Central India: A rural medical college hospital based data. Indian J Hum Genet. 2010;16(3):159-163.

7. Ansari I, Adhikari N. Perinatal mortality in Patan Hospital. J Nepal Health Res Counc. 2003;3:42-5.

8. Malla BK. One year review study of congenital anatomical malformation at birth in Maternity Hospital (Prasutigriha), Thapathali, Kathmandu. KUMJ. 2007;20:557-60.

9. Ansari I, Rajbhandari R, Chilise S, Shalh G, Maskey P, Maharjan R, Yadav R, Manandhar B, Ansari R. Congenital malformations at birth in 7,922 consecutive deliveries at Patan Hospital, Nepal. JPAHS. 2014;1(2):4-7.

10. Mohanty C, Mishra OP, Das BK, Bhatia BD, Singh G. Congenital malformations in newborns: A study of 10,874 consecutive births. J Anat Soc India. 1989;38:101-11.

11. Chaturvedi P, Banerjee KS. Spectrum of congenital malformations in the newborns from rural Maharashtra. Indian J Pediatr. 1989;56:501-7.

12. Suguna Bai NS, Mascarene M, Syamalan K, Nair PM. An etiological study of congenital malformation in the newborn. Indian Pediatr. 1982;19:1003-7.

13. Mathur BC, Karan S, Vijaya Devi KK. Congenital malformations in the newborn. Indian Pediatr. 1975;12:179.

14. Hudgins L, Cassidy SB. Congenital anomalies. In: Martin RJ, Fanaroff AA, Walsh MC, editors. Neonatal-Perinatal Medicine. 8th ed. Philadelphia: Mosby-Elsevier; 2006: 561-81.

15. Madi SA, Al-Naggar RL, Al-Awadi SA, Bastaki LA. Profile of major congenital malformations in neonates in AlJahra region of Kuwait. East Mediterr Health J. 2005;11:700-6.

16. Al-Gazali LI, Dawodu AH, Sabarinathan K, Varghese $M$. The profile of major congenital abnormalities in the United Arab Emirates (UAE) population. J Med Genet. 1995;32:7-13.

17. Mutchinick OM, Luna-Munoz L, Amar E, Bakker MK, Clementi M. Conjoined Twins: A Worldwide Collaborative Epidemiological Study of the International Clearinghouse for Birth Defects Surveillance and Research. Am J Med Genet C Semin Med Genet. 2011;157:274-287. 